\title{
DIAGNOSTICO TÉCNICO DOS PRODUTORES RURAIS, SOBRE O USO CORRETO E \\ CALIBRAÇÃO DE EQUIPAMENTOS PULVERIZADORES VISANDO A REDUÇÃO DO RISCO AMBIENTAL CAUSADO POR AGROTÓXICOS
}

TECHNICAL DIAGNOSIS OF RURAL PRODUCERS, ON THE CORRECT USE AND CALIBRATION OF SPRAY EQUIPMENT AIMED AT REDUCING THE ENVIRONMENTAL

RISK CAUSED BY PESTICIDES

Gentil Carneiro Gabardo ${ }^{1}$

Gilmar Knecht ${ }^{2}$

Keli Cristina dos Santos ${ }^{3}$

Caroline de Fátima Esperança ${ }^{4}$

Vinicius Guzi ${ }^{5}$

Elizandro Fochesatto ${ }^{6}$

Recebido em: 02 ago. 2020

Aceito em: 26 out. 2020

\section{RESUMO}

O objetivo deste trabalho foi identificar as maiores dificuldades que os produtores enfrentam no momento de fazer uso de equipamentos aplicadores de agrotóxicos, bem como avaliar o nível de conhecimento técnico que os produtores e operadores

\footnotetext{
${ }^{1}$ Eng. Agro. Doutor em Produção Vegetal, Professor do curso de Agronomia, Universidade Alto Vale do Rio do Peixe - Uniarp. Email: ge.gabardo@gmail.com / gentil@uniarp.edu.br

${ }^{2}$ Acadêmico do curso de Agronomia, Universidade Alto Vale do Rio do Peixe - Uniarp. Email: gima_knecht@hotmail.com

${ }^{3}$ Enga a . Agro[. Doutoranda em Produção Vegetal, Universidade do Estada de Santa Catarina - UDESC. Email: santtos_keli@yahoo.com.br

${ }^{4}$ Enga . Agro ${ }^{a}$. Mestra em Produção Vegetal, Professora do curso de Agronomia, Universidade Alto Vale do Rio do Peixe - Uniarp. Email: caroline.esperanca@uniarp.edu.br

${ }^{5}$ Acadêmico do curso de Agronomia, Universidade Alto Vale do Rio do Peixe - Uniarp. Email: viniguzi@hotmail.com

${ }^{6}$ Eng. Agro. Mestre em Fitotecnia/agroclimatologia, Professor do curso de Agronomia, Universidade Alto Vale do Rio do Peixe - Uniarp. Email: elizandro@uniarp.edu.br
} 
de equipamentos aplicadores de agrotóxico sobre a tecnologia de aplicação e a segurança ambiental, no município de Rio das Antas-SC, Região do Alto Vale do Rio do Peixe. Durante o período de realização do estudo, foram feitas visitas aos produtores, nas quais, coletaram-se dados sobre o nível de conhecimento dos produtores, sobre as condições dos equipamentos; uso correto e cuidados tomados; por meio da aplicação de questionários previamente elaborados e inspeções nos equipamentos aplicadores. Pequenos agricultores relatam, em sua maioria, uma grande carência de informação e assistência técnica relacionada a tecnologia de aplicação. Muitas vezes desconhecem totalmente o processo de regulagem e calibração dos equipamentos. Equipamentos antigos são facilmente observados nas pequenas propriedades, muitas vezes, castigados pelas condições de uso. A falta de manutenção é um fator limitante ao bom funcionamento dos pulverizadores, bem como, para a eficiência dos produtos aplicados. A identificação das maiores dificuldades que os agricultores enfrentam, no dia a dia, para realização da aplicação dos defensivos agrícolas, bem como o nível de conhecimento que estas pessoas tem sobre o risco que estão expostas ao trabalhar com agrotóxicos, é de fundamental importância para a elaboração e desenvolvimento de políticas públicas que venham a promover a capacitação e aperfeiçoamento do homem do campo.

Palavras-chave: Tecnologia de aplicação, defensivos agrícolas, impacto ambiental.

\section{ABSTRACT}

The aim of this work was to identify the greatest difficulties that producers face when using pesticide application equipment, as well as to evaluate the level of technical knowledge that producers and operators of pesticide application equipment on application technology and environmental safety, in the municipality of Rio das Antas-SC, in the Alto Vale do Rio do Peixe Region. During the study period, visits were made to the producers, in which data were collected on the level of knowledge of the producers, on the conditions of the equipment; correct use and care taken; through the application of previously prepared questionnaires and inspections of the applicator equipment. Most small farmers report a great lack of information and technical assistance related to application technology. Often they are completely unaware of the regulation and calibration process of the equipment. Old equipment is easily observed in small properties, often punished by the conditions of use. The lack of maintenance is a limiting factor for the good functioning of the sprayers, as well as for the efficiency of the applied products. The identification of the greatest difficulties that farmers face, on a daily basis, to carry out the application of pesticides, as well as the level of knowledge that these people have about the risk they are exposed to when working with pesticides, is of 
fundamental importance for the elaboration and development of public policies that will promote the training and improvement of rural people.

Keywords: Application technology, pesticides, environmental impact.

\section{INTRODUÇÃO}

O uso inadequado de defensivos químicos é tido por muitos como o grande vilão para a saúde humana nos últimos anos. Os procedimentos agrícolas têm evoluído para que sejam mais eficientes, com novas estratégias para diminuir os custos de produção, de modo que a agricultura continue sendo viabilizada (OLIVEIRA; DALCHIAVON, 2019). O consumo de certos alimentos está associado ao surgimento e desenvolvimento de enfermidades, pois muitas vezes o limite de carência dos produtos não é respeitado, ou mesmo, as doses aplicadas excedem as recomendações técnicas, ou ainda os equipamentos de aplicação estão em condições precárias e cuidados necessários para a aplicação segura não são tomados (MARQUES; NEVES; VENTURA, 2010).

Resíduos de alguns produtos químicos podem ser carcinogênicos, e quando estes atingem córregos, rios e mananciais por meio de enxurradas podem promover elevado impacto ambiental e aumento de riscos à saúde humana. Segundo dados do INCA (Instituto Nacional de Câncer José Alencar Gomes Da Silva), para o Brasil, estimam-se 68.220 casos novos de câncer de próstata para cada ano do biênio 2018-2019. Esses valores correspondem a um risco estimado de 66,12 casos novos a cada 100 mil homens. Sem considerar os tumores de pele não melanoma, o câncer de próstata é o mais incidente entre os homens em todas as Regiões do país, com 96,85/100 mil na Região Sul, 69,83/100 mil Região na Sudeste, 66,75/100 mil na Região Centro-Oeste, 56,17/100 mil na Região Nordeste e 29,41/100 mil na Região Norte. Para o câncer de mama, estimam-se 59.700 casos novos, para cada ano do biênio 2018-2019, com um risco estimado de 56,33 casos a cada 100 mil mulheres. Sem considerar os tumores de pele não melanoma, esse tipo de câncer também é o primeiro mais frequente nas mulheres das Regiões Sul (73,07/100 mil), Sudeste (69,50/100 mil), Centro-Oeste (51,96/100 mil) e Nordeste $(40,36 / 100$ mil). Na Região Norte, é o segundo tumor mais incidente $(19,21 / 100$ mil). 
Tais dados causam muita preocupação, visto que muitas vezes, os agrotóxicos são citados como os grandes vilões à saúde humana, principalmente, devido ao seu potencial carcinogênico. O herbicida glifosato, que frequentemente é utilizado em nossa região para várias culturas, principalmente para a culturas transgênicas, como a soja e milho, é relato por vários autores como promotor do desenvolvimento de tumores: Thongprakaisang et al (2013) em estudo preliminares detectaram interação entre glifosato e genisteína, um fitoestrógeno da soja, tal interação leva ao aumento da atividade estrogênica, que por sua vez aumenta as chances do desenvolvimento de células cancerosas relacionadas ao câncer de mama, ou seja, glifosato induz crescimento células cancerosas em mamas humanas através dos receptores de estrogênio.

Neste contexto os estudos de tecnologias de aplicação que observam principalmente as condições dos equipamentos e o conhecimento técnico do aplicador, levando em conta as características do equipamento que utiliza, bem como, os procedimentos técnicos envolvidos na aplicação são de suma importância para evitar danos ambientais, econômicos e aumentar a eficiência do defensivo ao atingir o alvo específico. Este trabalho foi desenvolvido junto com a comunidade, para identificar as maiores dificuldades que os produtores enfrentam no momento de fazer uso de equipamentos aplicadores de agrotóxicos, bem como avaliar o nível de conhecimento técnico que os produtores e operadores de equipamento aplicador de agrotóxico tem sobre medidas a serem tomadas para garantir a qualidade da aplicação, a segurança ambiental, a economia e a saúde humana, no município de Rio das Antas-SC, Região do Alto Vale do Rio do Peixe.

\section{MATERIAIS E MÉTODOS}

O presente foi conduzido em parceria com cooperativa agrícola, situada no município de Rio das Antas-SC. Realizaram-se coletas de dados nas comunidades rurais no interior do município de Rio das Antas-SC, durante os meses de abril de 2019 a março de 2020.

Inicialmente foram distribuídos convites ao maior número de agricultores de comunidades pré-selecionadas e até mesmo vizinhos. Convites, estes, para uma palestra inicial realizada em espaço cedido pela cooperativa. 
Na palestra inicial, abordaram-se os seguintes temas:

1. Importância econômica e ambiental do controle de aplicação;

2. Regulagem e calibração de pulverizadores;

3. Volume de calda por hectare;

4. Qualidade da aplicação dos produtos fitossanitários;

5. Cuidados durante o processo de aplicação;

6. Utilização do EPI (Equipamento de Proteção Individual);

7. Estudo de dosagens e recomendações técnicas;

8. Manutenção preventiva de equipamentos de aplicação;

9. Perdas econômicas e desequilíbrio ambiental;

10. Abordagem prática da forma correta de calibragem dos equipamentos.

Posteriormente a palestra, foram distribuídos materiais de apoio aos presentes, e agendadas visitas as propriedades dos produtores, para que o maior número de pessoas fosse atendido, dentro de sua disponibilidade de tempo.

Na visita aos produtores, realizaram-se os seguintes procedimentos:

1. Aplicação de questionário focado na identificação dos equipamentos e conhecimento técnico dos produtores;

2. O produtor foi indagado sobre a realização de manutenções no equipamento;

3. Processo de vistoria do equipamento, lembrando que para isto, o uso de EPI é obrigatório para todos os envolvidos. Verificados inicialmente os componentes básicos do equipamento (mangueiras, filtros, manômetros, bicos e pontas de pulverização);

4. Com o pulverizador previamente lavado e abastecido apenas com água, realizou-se o processo de calibração, com a coleta do volume de calda depositado por cada ponta em um determinado tempo; com isso, pode-se estimar o volume de calda que o pulverizador está aplicando em uma determinada área, pela seguinte equação:

$$
Q_{(L / h a)}=\frac{q_{(L / \mathrm{min})} x 600}{V_{(K m / h)} x h_{(m)}}
$$


Onde: $\mathrm{Q}=$ vazão em litros por hectare;

$q$ = vazão média da ponta de pulverização (L/min);

600 = valor constante;

$V=$ velocidade da máquina $(\mathrm{km} / \mathrm{h})$;

$h=$ distância entre pontas de pulverização $(\mathrm{m})$.

Determinação da velocidade média das máquinas: delimita-se uma faixa de $50 \mathrm{~m}$ lineares, onde o produtor deve se deslocar com o trator, na marcha, rotação e velocidade de aplicação que normalmente utiliza para aplicação dos defensivos agrícolas. Cronometrado o tempo de percurso dos $50 \mathrm{~m}$ (t1 (segundos)), para realizar o cálculo de velocidade do trator $(\mathrm{V}-\mathrm{Km} / \mathrm{h})$ no momento da aplicação:

$$
V_{(K m / h)}=\left(\frac{3600 \times 50}{t_{1}}\right) / 1000
$$

5. Feita a coleta da vazão das pontas de pulverização, utilizou-se a média ponderada, para verificar a uniformidade da vazão das pontas, considerando um limite aceitável de 5 a 10\%, para mais ou para menos;

6. Caso o pulverizador não estivesse funcionando corretamente, foram apontadas alternativas ao produtor solucionar o problema (ex: substituição das pontas de pulverização; aumento ou diminuição da velocidade de aplicação; adequação da pressão às pontas utilizadas etc.).

\section{RESULTADOS E DISCUSSÕES}

\section{CUIDADOS DURANTE O PREPARO E APLICAÇÃO DE AGROQUÍMICOS}

A situação observada na região de estudo nos traz um alerta para a questão de saúde pública e ambiental. O uso de produtos químicos para controle de pragas e doenças nas lavouras exige certo conhecimento técnico em relação as dosagens e formas com que devem ser aplicados. Percebeu-se que muitos produtores são carentes em informações básicas sobre o uso correto doa 
defensivos, muitos deles nem leem o receituário ou bula dos produtos. Estudo semelhante realizado por Marques, Neves, Ventura (2010), com intuito de diagnosticar o conhecimento de informações básicas para o uso de agrotóxicos por produtores rurais de hortaliças da região de Londrina - PR, dando ênfase ao entendimento dos rótulos e bulas pelos mesmos, constatou que as maiores dificuldades apresentadas pelos produtores foram a compreensão do conteúdo (linguagem técnica) e o tamanho reduzido das letras. Os pictogramas, as faixas de cores e termos importantes para a segurança na utilização de agrotóxicos não foram compreendidos pela maioria dos agricultores. Os inseticidas foram os produtos mais utilizados e responsáveis pelo maior número de intoxicações.

É preocupante a questão de intoxicações ocorridas durante o preparo, manipulação e aplicação dos agrotóxicos, visto que alguns produtores entrevistados relataram já terem tido problemas com produtos. A maior parte dos casos de intoxicação por agrotóxicos se deve ao fato dos produtores não fazerem uso correto dos equipamentos de proteção individual -EPI, ou uso do equipamento inadequado ou incompleto. Como pode ser visto na Figura 01, apenas $60 \%$ dos entrevistados utilizam o traje de proteção macacão ou jaleco e calça hidrorepelente. Todos alegam fazer uso de luvas durante a manipulação e aplicação dos produtos, porem metade deles deixa de usar a touca árabe, apenas $55 \%$ possuem respiradores com carvão ativado, $65 \%$ dos entrevistados não utilizam óculos de proteção e apenas $20 \%$ deles possui e usa a mascara facial completa (respirador, touca árabe, viseira).

Figura 01 - Identificação de equipamentos de proteção individual (EPIs) e a porcentagem de adesão desses equipamentos pelos produtores entrevistados. Rio das Antas - SC, 2020. 


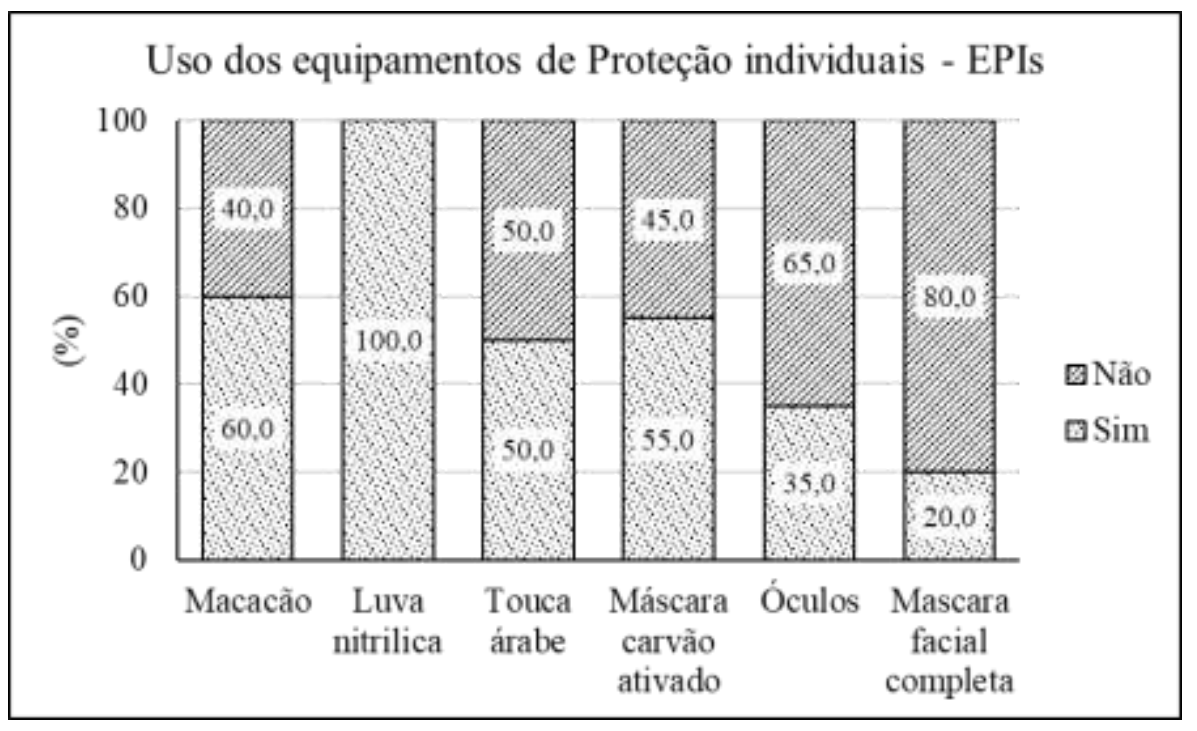

CONDIÇÕES DOS EQUIPAMENTOS DE APLICAÇÃO DE AGROQUÍMICOS

Ao avaliar as características físicas e condições de uso dos equipamentos aplicadores de agrotóxicos de posse dos entrevistados, Figura 02, foi identificado que o tipo de pulverizador de barras predominantemente utilizado pelos produtores, 45\%, tem comprimento de barras de 12 metros. E que a maior parte dos produtores tem esses equipamentos há mais de 13 anos na propriedade, e que em grande parte dos casos a manutenção deles é deficiente. Com relação aos componentes, todos os equipamentos apresentavam manômetros, filtros de linhas e de bicos, assim como todos os produtores possuíam um copo ou jarra de calibração, porem alguns tinham dificuldade ou não sabiam utilizar o equipamento. O incorporador lateral foi observado na maior parte dos pulverizadores.

Figura 02 - Dimensões das barras de aplicação (A), idade dos equipamentos (B), identificação de componentes e presença deles (C) nos equipamentos de pulverização dos produtores entrevistados. Rio das Antas - SC, 2020. 


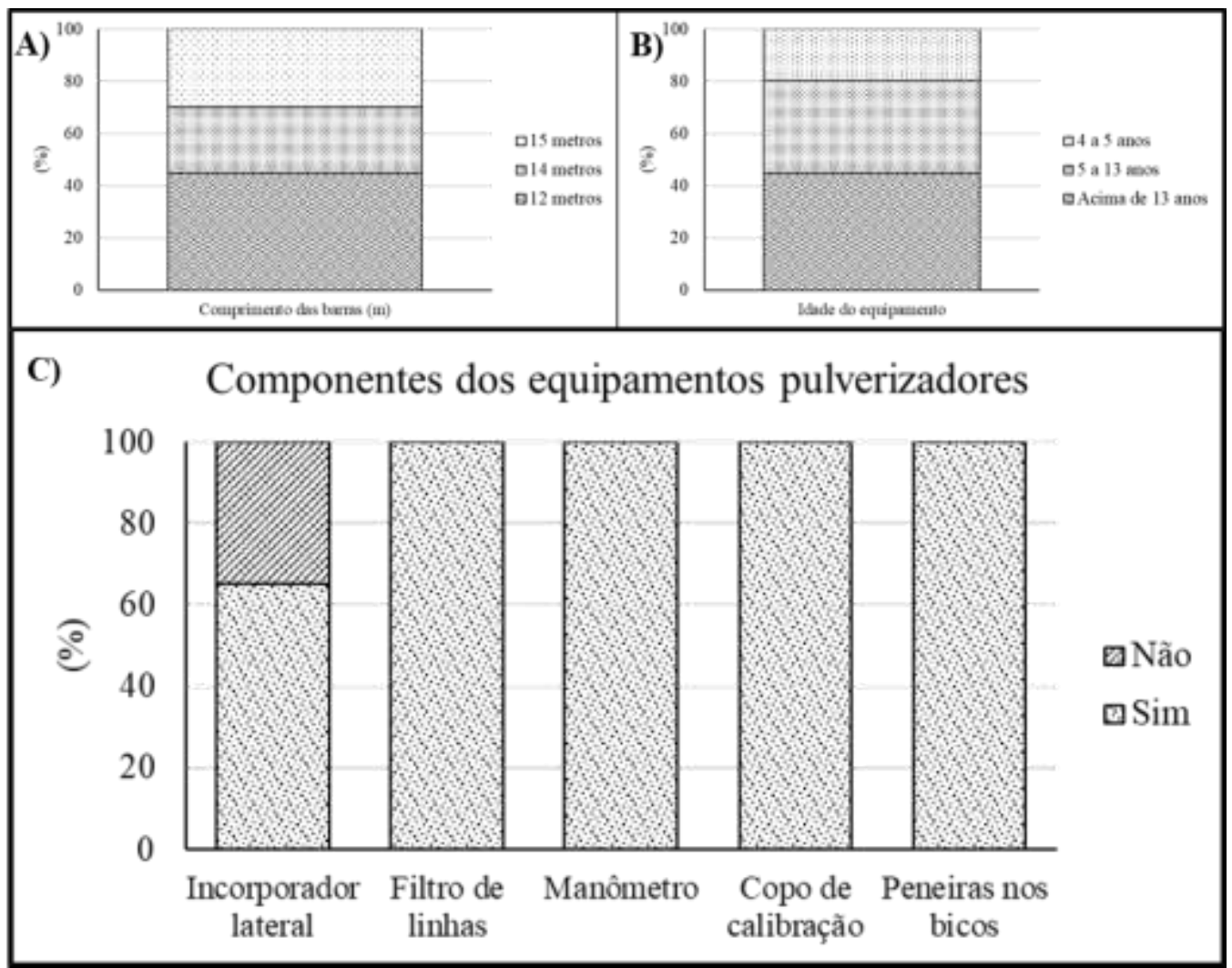

Com relação as pontas de pulverização encontradas nas propriedades dos entrevistados, as postas do tipo leque foram as principais. Sendo que $35 \%$ dos produtores possuíam apenas um jogo de pontas de pulverização disponível para uso, 65\% deles possuíam dois conjuntos de pontas disponíveis. Quanto aos pulverizadores, $70 \%$ deles possuía o sistema de porta bicos nonojet (apenas uma ponta), 30\% possuíam sistema bijet.

Pequenos agricultores relatam, em sua maioria, uma grande carência de informação e assistência técnica na área de tecnologia de aplicação. Muitas vezes desconhecem totalmente o processo de regulagem e calibração dos equipamentos e máquinas aplicadoras de agrotóxicos. Equipamentos mais antigos são facilmente observados nas pequenas propriedades, muitas vezes, castigados pelas condições de uso. A falta de manutenção é um fator limitante ao bom funcionamento dos pulverizadores, bem como, para a eficiência dos produtos aplicados. Em diversos locais a situação é semelhante e alarmante, como relatam Costa, Tarsitano \& Conceição (2012), que ao realizar acompanhamento de produtores de uvas 
perceberam que a maioria dos produtores não conta com assistência técnica regular, não segue recomendações de adubação e não emprega critérios técnicos para o manejo da irrigação, o controle de doenças é realizado de forma preventiva e intensa, chegando a superar 100 aplicações por ciclo, no caso das uvas finas para mesa.

\section{CONHECIMENTO TÉCNICO DOS PRODUTORES E OPERADORES DE MÁQUINAS}

\section{APLICADORAS DE AGROQUÍMICOS}

Agricultores de maior poder aquisitivo investem em equipamentos mais modernos, com sistemas de controle elétrico ou eletrônico, com maiores capacidades de reservatório de calda e maior superfície de aplicação. No entanto, também pecam na parte de limpeza e manutenção dos equipamentos. Para Oliveira et al. (2009) o uso excessivo e sem informação técnica de qualidade sobre os produtos fitossanitários provoca diversos danos, principalmente sobre o próprio solo, da água, do ar, das plantas e dos animais, refletindo diretamente na vida do produtor que utiliza desses elementos para sobrevivência. Sendo a utilização inadequada de tecnologia de aplicação de produtos fitossanitários considerada como uma das principais causas de contaminação do meio ambiente afetando a biologia existente nesse ecossistema.

Muitos desconhecem as boas práticas de manejo e manutenção dos equipamentos, deixando os equipamentos guardados sem a devida limpeza, deixam com restos de calda, não lavam os componentes filtrantes. Somente substituem as pontas de pulverização quando se quebram. Não monitoram a qualidade da aplicação que está sendo realizada pelo equipamento. A tecnologia de aplicação, atua diretamente na aplicação de um produto químico com a utilização de equipamento adequado, afetando o alvo biológico com eficiência, economia e segurança. A aplicação correta requer conhecimentos técnico e específico da molécula química do defensivo para que chegue ao alvo, afetando somente o patógeno desejável, de forma a evitar a contaminação do ambiente e a qualidade de vida do aplicador (MACHADO NETO et al. 2007).

Para que uma aplicação seja eficiente deve respeitar alguns requisitos como, o produto seja depositado no alvo e que atue da maneira esperada e com a 
eficácia desejada. Sendo assim vai garantir principalmente economia nos procedimentos operacionais refletindo na segurança no momento da aplicação, para o ambiente, trabalhador e consumidor (BAUER et al. 2009; COSTA et al., 2007).

As visitas realizadas nas propriedades foram muito construtivas para todos os envolvidos. O processo de aferição da vazão e calibração dos equipamentos (Figura 03), despertou muito o interesse dos produtores, pois foi evidenciado o quanto de produto estava sendo aplicado e a qualidade dessa aplicação. O excesso de calda aplicado, ou mesmo a aplicação desuniforme, interfere diretamente na eficiência dos tratamentos fitossanitários, além de aumentar significativamente os custos de produção, desenvolvimento de plantas daninhas resistentes, desequilíbrio e contaminação ambiental. 
Figura 03 - Aferição da vazão de pulverizadores de barras, calibração e avaliação da qualidade da aplicação (papel hidro sensível). Rio das Antas - SC, 2020.

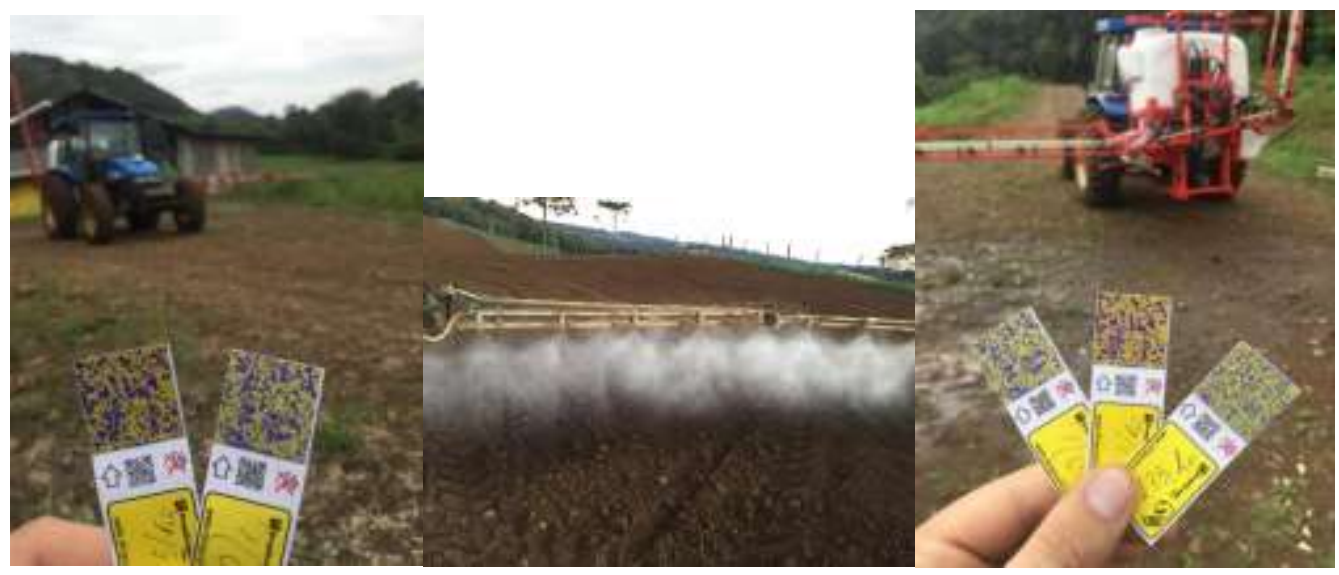

Muitos agricultores desconhecem a influência que a pressão de trabalho tem sobre a qualidade da aplicação, visto que, além de afetar diretamente a vazão influencia o tamanho das gotas geradas, bem como aumenta a chance de perda por deriva dependendo do tipo de ponta de pulverização utilizada. A redução na pressão pode ser utilizada para controle de deriva, mas a seleção adequada de uma ponta mostrou ser mais eficiente para esse propósito (COSTA et al., 2007).

\section{CONCLUSÃO}

Com a chegada de novos equipamentos para aplicação de agrotóxicos, os trabalhos de controle de pragas e doenças nas lavouras ficaram cada vez mais fáceis de ser realizado, porem para garantir a qualidade de aplicação devem ser adotados alguns métodos de avaliação dos pulverizadores e seus componentes a fim de identificar possíveis problemas de pressão, vazão (litros por minuto) e entupimento das pontas de pulverização. A redução do impacto causado pelos agrotóxicos deverá ser garantida com a aplicação consciente e segura, feita com equipamentos corretamente revisados e calibrados. Os produtores que seguirem à risca os métodos de calibração dos pulverizadores diminuirão o impacto ambiental e consequentemente reduzindo os gastos com insumos (defensivos/agrotóxicos).

A conscientização dos agricultores é fundamental para evitar o desequilíbrio ambiental e perdas econômicas, as condições de conservação e 
manutenção dos equipamentos utilizados para realizar a aplicação dos produtos agrotóxicos devem ser as melhores possíveis. Pois a utilização de equipamentos desgastados promove uma aplicação desuniforme causando desperdício e comprometendo o meio ambiente.

Na maioria das vezes o pequeno e médio produtor rural apresenta uma grande carência de informação na área de tecnologia de aplicação, ficando a mercê de técnicos que o orientem sobre as melhores técnicas a serem utilizadas para identificar possíveis defeitos nos equipamentos.

\section{AGRADECIEMNTOS}

Os autores agradecem ao Fundo de Apoio à Pesquisa - FAP da Universidade Alto Vale do Rio do Peixe - UNIARP, pelo apoio recebido durante a execução deste trabalho.

\section{REFERÊNCIAS}

BAUER, F.C.; PEREIRA, F.de A.R.; SCHEEREN, B.R.; BRAGA, L.W. Diagnóstico das condições, tempo de uso e manutenção de pulverizadores no estado de Mato Grosso do Sul. Engenharia Agrícola, Jaboticabal, v.29, n.3, p.501-507, jul./set, 2009. https://dx.doi.org/10.1590/S0100-69162009000300017

COSTA, A.G.F.; VELINI, E.D.; NEGRISOLI, E.; CARBONARI, C.A.; ROSSI, C.V.S.; CORRÊA, M.R.; SILVA, F.M.L. Efeito da intensidade do vento, da pressão e de pontas de pulverização na deriva de aplicações de herbicidas em pré-emergência. Planta Daninha, Viçosa-MG, v. 25, n. 1, p. 203-210, 2007. http://dx.doi.org/10.1590/S0100-83582007000100023

COSTA, T.V.D., TARSITANO, M.A.A., CONCEIÇÃO, M.A.F. Caracterização social e tecnológica da produção de uvas para mesa em pequenas propriedades rurais da região de Jales-SP. Revista Brasileira de Fruticultura, 34(3), 766-773, 2012. https://doi.org/10.1590/S0100-29452012000300016

INCA - INSTITUTO NACIONAL DE CÂNCER JOSÉ ALENCAR GOMES DA SILVA Estimativa 2018: incidência de câncer no Brasil / Instituto Nacional de Câncer José Alencar Gomes da Silva. Coordenação de Prevenção e Vigilância. - Rio de Janeiro: INCA, 2017. 128p. 
MACHADO NETO, J.G.; COSTA, G.M.; OLIVEIRA, M.L. Segurança do trabalhador em aplicações de herbicidas com pulverizadores de barra em cana-de-açúcar. Planta Daninha, Viçosa-MG, v. 25, n. 3, p. 639-648, 2007.

http://dx.doi.org/10.1590/S0100-83582007000300025

MARQUES, C.R.G.; NEVES, P.M.O.J.; VENTURA, M.U. Diagnóstico do conhecimento de informações básicas para o uso de agrotóxicos por produtores de hortaliças da Região de Londrina. Semina: Ciências Agrárias, Londrina, v. 31, n. 3, p. 547-556, jul./set. 2010. https://www.redalyc.org/pdf/4457/445744097003.pdf

OLIVEIRA, V. C.; DALCHIAVON, F. C., Investimentos na aplicação de defensivos agrícolas na região do Médio-Norte do estado Matogrossense. Revista de Ciências Agrárias, 2019, 42(1): 283-293. DOI:: https://doi.org/10.19084/RCA18176

THONGPRAKAISANG, S., THIANTANAWAT, A., RANGKADILOK, N., SURIYO, T., SATAYAVIVAD, J. Glyphosate induces human breast cancer cells growth via estrogen receptors. Food Chemical Toxicology. 59:129-36. doi: 10.1016/j.fct.2013.05.057. Epub 2013 Jun 10. 2013. 